\title{
Produção de móveis rústicos com madeira residual da floresta Amazônica
}

\author{
Germano Slominski BURAKOUSKI*, Everton HILLIG ${ }^{1}$, Fabiane Salles FERRO', \\ Gabriel de Magalhães MIRANDA 1 \\ ${ }^{1}$ Setor de Ciências Agrárias e Ambientais, Universidade Estadual do Centro Oeste, Irati, PR, Brasil. \\ *E-mail: germanoengf@gmail.com \\ (ORCID: 0000-0003-4092-7567; 0000-0002-7895-2453; 0000-0003-0071-9472; 0000-0001-8536-6658)
}

\begin{abstract}
Recebido em 31/08/2021; Aceito em 12/11/2021; Publicado em 17/12/2021.
RESUMO: A exploração madeireira e as conversões de áreas de florestas para uso alternativo do solo na região Amazônica, em especial no estado do Amapá, resultam em grandes quantidades de madeira residual que em geral são abandonadas em campo. Essa problemática da geração de resíduos florestais e principalmente do desperdício e da falta de alternativas para o seu uso apropriado, resultou nesta proposta de pesquisa que teve como objetivo a produção de móveis rústicos artesanais como uma alternativa para o uso da madeira residual da floresta Amazônica. Foram coletados resíduos de madeira deixados no campo após a colheita de floresta Amazônica manejada, destinando-os à fabricação de mobiliário rústico, obtendo como resultado final os seguintes protótipos: banco peça de tora única, balcão para barzinho, aparador de madeira, pia de madeira, mesinha de centro com tampo de madeira, mesinha de centro com tampo de vidro. Foi testada a viabilidade técnica para fabricação artesanal das peças de mobiliário utilizando máquinas e ferramentas portáteis. Os resíduos de madeira se mostraram excelente fonte de matéria-prima para movelaria rústica possibilitando múltiplas alternativas de designs, apesar de certas dificuldades terem sido evidenciadas no decorrer do processo como: peso, dureza, orientação da grã da madeira, entre outras que, no entanto, não impossibilitaram a produção dos móveis. O uso da madeira residual para fabricação de móveis rústicos pode se constituir num novo e empreendedor negócio para a região Amazônica, contribuindo para a geração de renda local. Verificouse que o método empregado proporcionou a produção de móveis originais, o que agrega valor à sua comercialização.
\end{abstract}

Palavras-chave: trabalho artesanal; empreendedorismo; projeto.

\section{Rustic furniture production with wood residues from the Amazon forest}

\begin{abstract}
Harvesting and conversions of forest areas to alternative land use in the Amazon region, especially in the Amapá state, result in large amounts of wood residues that are generally abandoned. This problem about the forest residues and mainly of its loss and the lack of alternatives for its proper use, resulted in this research proposal that aimed to produce handcrafted rustic furniture as an alternative to the use of wood residues from the Amazon forest. Wood residues left in the field after harvesting the managed Amazon forest were collected and destined for the manufacture of rustic furniture, obtaining the following prototypes as a final result: $\log$ bench, bar counter, wood dresser, wood sink, coffee table with wood top, coffee table with glass top. The technical feasibility of handcrafting furniture pieces using portable machines and tools were tested. Wood residues proved to be an excellent source of raw material for rustic furniture, enabling multiple design alternatives, although certain difficulties were evidenced during the process such as: weight, hardness, wood grain orientation, among others that did not prevent the furniture production. The use of wood residues to rustic furniture manufacture can constitute a new and entrepreneurial business for the Amazon region, contributing to the generation of local income. It was found that the method used provided the production of original furniture, which adds value to its marketing.
\end{abstract}

Keywords: artisan work; entrepreneurship; design.

\section{INTRODUÇÃO}

Dados do Instituto de Comunicação e Informação Científica e Tecnológica em Saúde e Fundação Oswaldo Cruz do ano de 2019, apontam a Região Amazônica como sendo a maior área de floresta tropical do mundo, contendo, aproximadamente, um quarto de todas as florestas tropicais do planeta, mas que figura entre as regiões que possuem as maiores taxas de desmatamento (ICICT; FIOCRUZ, 2019).

Nessa região, em especial no estado do Amapá, ainda é comum a limpeza de áreas para fins de uso alternativo do solo executada com a utilização de ferramentas manuais (machado, foice) ou com o uso de motosserras, sem a "destoca" com máquinas (tratores), prática que costumeiramente gera excedentes de resíduos de madeira nativa no campo.

A atividade florestal na Amazônia gera grandes quantidades de resíduos, principalmente durante a colheita $(9-18 \%)$ e no processo de beneficiamento das toras (4555\%)" (NUMAZAWA et al, 2017; SILVA et al, 2020). Os resíduos deixados na floresta nativa por ocasião da exploração florestal podem ser os mais variados possíveis, a 
exemplo: tocos cortados altos do chão, madeira de espécies não previstas para corte que são derrubadas com o corte de árvores maiores ou eventualmente presas a cipós e às árvores de corte, galhadas, bifurcações, sapopemas, partes tortuosas de troncos e galhos, seções ocas de toras, madeira proveniente de queda natural da árvore ou partes dessas madeiras (cerne), restos de desdobro de toras por eventual uso para infraestrutura local (pontes, barracos, etc.).

Conforme Silva et al (2020) "a carbonização é uma alternativa potencial para mitigar este passivo", embora essa alternativa local na maioria das vezes apresente-se inviável devido ao trabalho gerado, aos custos de transporte em áreas mais remotas e ao preço de venda relativamente baixo, condições que desmotivam tal uso.

Braz et al (2014) aponta que os resíduos oriundos da floresta são desperdiçados, muitas vezes em função de não saberem aproveitá-los ou por falta de opções tecnológicas. Dessa forma, grandes quantidades de madeiras, nobres ou não, são abandonadas no campo, condição essa que sensibilizou a busca por alternativa que pudesse agregar valor e dar aproveitamento a esses resíduos.

A alternativa então pensada para uso desses resíduos foi a de produzir artesanalmente diferentes peças de mobiliário rústico aproveitando como matéria-prima a madeira residual da floresta nativa da Amazônia.

Diferentemente do trabalho industrial, o processo artesanal de produção de móveis é realizado com as próprias mãos ou por meio da utilização de ferramentas simples. Assim, a natureza do trabalho artífice permite que o trabalhador tome contato físico com o produto (VIEIRA, 2014).

As mãos, enquanto ferramentas possibilitam que o artesão trabalhe o objeto a fim de que este se torne equivalente ao que foi mentalmente projetado pelo artesão (HERNANDES, 2016). Neste caso trata-se de fabricação do mobiliário em pequena escala, com forte apelo artesanal, devido a especificidade de cada peça, idealizada de acordo com a matéria prima disponível, ou seja, a peça é produzida em função do material obtido, sem um design pré-formatado, por isso na maioria das vezes o resultado real do trabalho somente é conhecido ao finalizar o móvel.

\section{MATERIAL E MÉTODOS}

O trabalho desenvolvido utilizou material residual doado de área de Plano de Manejo Florestal legalizada. Na área do PMFS foram coletados resíduos de galhadas, resíduos de árvores derrubadas com a queda de árvores maiores, resíduos de madeira desdobrada na floresta com a finalidade de serem utilizadas na infraestrutura do manejo, resíduos de madeira provenientes de queda natural da árvore e ainda peças de madeira (partes de troncos) encontradas já deterioradas pelo tempo, algumas parcialmente enterradas nas laterais da estrada de acesso.

Para as madeiras mais comumente comercializadas foram obtidos dados referentes a propriedades físicas e mecânicas destinado a fins comparativos entre as espécies. Para as madeiras sem tradição comercial não foram encontradas referências destas propriedades.

Os dados constantes na Tabela 1, referentes às propriedades físicas e mecânicas das espécies florestais de interesse, foram obtidos e adaptados de Araújo (2007), o qual indica a utilização de normas da COPANT e corpos de prova com um teor de umidade de $12 \%$.
Tabela 1. Propriedades físicas e mecânicas das espécies florestais. Table 1. Physical and mechanical properties of forest species.

\begin{tabular}{lrrrrr}
\hline \multirow{2}{*}{ Prop- } & \multicolumn{5}{c}{ Nome comum } \\
\cline { 2 - 6 } & Cast- & Suc- & Ang-V- & Ang-P- & Maç-. \\
\hline Pbas $\left(\mathrm{g} / \mathrm{cm}^{3)}\right.$ & 0,63 & 0,85 & 0,83 & 0,59 & 0,85 \\
$\mathrm{C}_{\mathrm{r}, 3}(\%)$ & - & 9 & 9,5 & 6,3 & 8,3 \\
$\mathrm{C}_{\mathrm{r}, 2}(\%)$ & - & 6 & 5,7 & 4,1 & 5,9 \\
fM $(\mathrm{Mpa})$ & 116,01 & 182,11 & 156,91 & 109,34 & 128,17 \\
EM0 $(\mathrm{Mpa})$ & 12553 & 17946 & 16966 & 11572 & 13533 \\
$\mathrm{fc} 0(\mathrm{Mpa})$ & 58,35 & 92,28 & 85,61 & 52,27 & 63,55 \\
Ec90 (Mpa) & 9,9 & 15,89 & 14,81 & 11,28 & 15,2 \\
fH0 (N) & 8071 & 14847 & 14318 & 7659 & 8698 \\
fH90 (N) & 6541 & 15200 & 13543 & 5786 & 9101 \\
fwt90 (Mpa) & 4,22 & 4,12 & 3,82 & 3,82 & 5,59 \\
fv0 (Mpa) & - & 6,57 & 6,57 & - & 4,31 \\
fs0 (Mpa) & 11,47 & 19,02 & 17,65 & 12,26 & 15,98 \\
\hline
\end{tabular}

Prop- = Propriedades; Cast- = Castanheira; Suc- = Sucupira; Ang-V- = Angelim vermelho; Ang-P- = Angelim pedra; Maç- = Maçaranduba; Pbas = densidade básica, $\epsilon_{\mathrm{r}, 3}=$ contração tangencial; $\Theta_{\mathrm{r}, 2}=$ contração radial; $\mathrm{fM}=$ módulo de ruptura à flexão estática; EM0 = módulo de elasticidade à flexão estática; fc $0=$ resistência à compressão paralela às fibras; Ec 90 : resistência no limite proporcional à compressão perpendicular às fibras; $\mathrm{fH} 0=$ dureza Janka paralela às fibras; fH $90=$ dureza Janka transversal às fibras; fwt $90=$ resistência à tração perpendicular às fibras; fvo $=$ resistência ao fendilhamento; $\mathrm{fs} 0=$ resistência ao cisalhamento.

Como a concepção das peças está atrelada à visão criativa de quem irá produzi-las, a escolha do material em campo é fundamental, pois ao visualizá-lo, o artesão deve ter em mente a ideia inicial do projeto, para que possa então cortálo apropriadamente de acordo com o dimensionamento da peça que mentalizou. Para se trabalhar esses resíduos foi necessário o uso de máquinas e ferramentas de corte, lixamento, escavação, modelagem, entalhamento, além de insumos aplicados nas diversas fases de criação das peças como verniz, cola, resina, etc.

Algumas das peças de mobiliário produzidas foram entalhadas para enobrecer a função estética do móvel, utilizando para isso somente ferramentas manuais (formões para entalhe). Em outras foram utilizados itens extras como vidros devidamente dimensionados para refinar o móvel e agregar mais valor ao produto final, utilizando-se de toda criatividade aplicada a concepção inicial da peça.

Todo o trabalho foi executado com máquinas e ferramentas domésticas (portáteis) e não industriais, de forma artesanal e simples, de modo a comprovar a possibilidade de fabricação do mobiliário sem aparatos sofisticados.

As espécies utilizadas são comuns na floresta amazônica, sendo que a experiência profissional com manejo de florestas nativas, aliado ao conhecimento empírico do serrador permitiu a fácil identificação para fins de classificação botânica.

\subsection{Fabricação do banco "peça de tora única"}

Este móvel foi criado a partir de um tronco de cedro vermelho (Cedrela fissilis Vell) parcialmente corrompido pelo apodrecimento, sendo a parte comprometida retirada com motosserra, cujo corte idealizado tornou a peça inteiriça tanto para o assento quanto para o encosto.

Também foi raspada toda a superfície externa da tora, comprometida pela podridão, deixando somente a parte íntegra da madeira que depois de totalmente seca (secagem ao ar livre) e limpa foi entalhada com imagem temática especificamente criada para este propósito, utilizando-se como fontes de inspiração imagens gratuitas, obtidas em sites da internet, adequando-as à visão panorâmica de cada projeto. 
Uma vez desenhada no papel em escala adequada ao projeto a imagem foi transposta à madeira, utilizando-se para isto o carvão aplicado ao verso da folha transformando-o em um tipo de papel carbono (Figura 1).
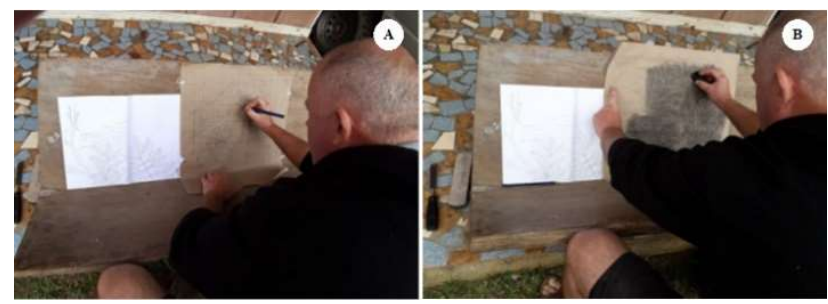

Figura 1. Desenho temático em escala no papel (A) e uso de carvão no verso do papel para facilitar a transposição do desenho na madeira (B).

Figure 1. Thematic scale drawing on paper (A) and use of charcoal on the paper back to facilitate the transposition of the drawing on $\operatorname{wood}(\mathrm{B})$.

Uma vez transposto o desenho à madeira deu-se início ao entalhe pretendido, com uso ferramentas específicas, como formões de diversos tamanhos e configurações de fio de corte, adicionando detalhamentos ao desenho à medida que este ganha contornos (Figura 2).
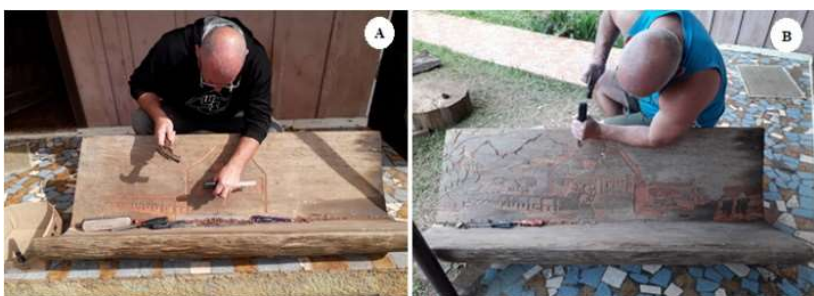

Figura 2. Entalhe na fase inicial (A) e entalhe do encosto do banco (AB).

Figure 2. Carving in the initial phase (A) and carving the seat back (B).

Nesta fase a maior dificuldade foi entalhar obedecendo a orientação da grã da madeira, condição que força o uso da ferramenta no sentido adequado para evitar lascas e não comprometer o desenho pretendido com a retirada acidental de partes não desejadas.

Foi entalhado tanto o encosto como assento do banco de forma a dar aspecto de continuidade ao desenho formando uma única imagem panorâmica. $\mathrm{O}$ entalhamento do banco foi a parte mais trabalhosa e demorada no processo de fabricação desta peça, devido a minuciosidade e delicadeza do trabalho.

Ainda na fase de criação da peça foi idealizada uma base (pés do banco) com travessas de madeira de castanheira-dobrasil (Bertholletia excelsa Bonpl), moldados para dar encaixe no formato angular da tora e ligados por uma barra longitudinal de madeira de sucupira-preta (Bowdichia nitida Spruce ex Benth), a qual foi travada com a própria madeira para dar firmeza à peça, sendo essa fixada ao assento com parafusos franceses. Para finalização do móvel, as partes externas do banco foram lixadas e o acabamento dado com verniz transparente para intensificar o brilho e destacar o entalhe (Figura 3).

Destaca-se que a espécie castanheira-do-brasil (Bertholletia excelsa Bonpl), é considerada em risco de extinção na floresta amazônica e por isso a legislação à protege do corte. Todas as peças desta espécie, utilizadas para fabricação dos móveis rústicos, foram provenientes de árvores caídas e parcialmente apodrecidas na floresta ou encontradas a beira das estradas de acesso.

Em áreas de supressão florestal autorizada todo o suprimento de madeira pode ser utilizado, mesmo madeira caída, já que a área toda será limpa. Em áreas de PMFS (Plano de Manejo Florestal Sustentável) não há controle de resíduos por espécie, como ocorre com a madeira em forma de fuste, portanto qualquer fonte de madeira residual pode ser explorada como resíduo desde que o volume estabelecido esteja dentro do montante estabelecido na AUTEX (Autorização de Exploração Florestal).

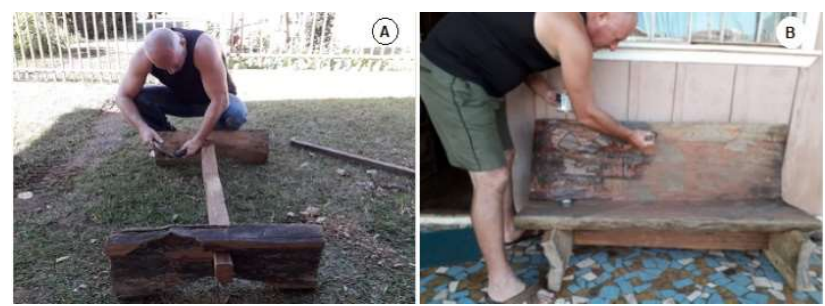

Figura 3. Detalhe da fabricação da base do banco (A) e acabamento com verniz transparente (B).

Figure 3. Detail of the seat base fabrication (A) and finish with transparent varnish (B).

\subsection{Fabricação do balcão para barzinho}

Dentre as peças produzidas para este estudo, o balcão para barzinho foi a maior em termos dimensionais já que a parte do balcão, proveniente de madeira de sucupira-preta (Diplotropis purpurea Rich) foi finalizada com 2,40 metros de comprimento e largura variável entre 0,5 e 0,7 metros, devido o seu formato irregular ao longo da peça.

Um fato interessante sobre esta peça de sucupira-preta é que a mesma foi encontrada semi-enterrada numa área de pastagem e sinais aparentes mostram que a mesma já havia resistido ao fogo, pois apresentava carbonização nas extremidades.

Notou-se também que a maior parte da tora havia sido consumida pelo apodrecimento restando apenas uma crosta em formato acanoado e superfície bastante irregular, deixando claro que a madeira ficou exposta por muito tempo na natureza e que esta foi a porção que resistiu às intempéries. Detalhes desta peça na configuração original podem ser vistos na Figura 4.

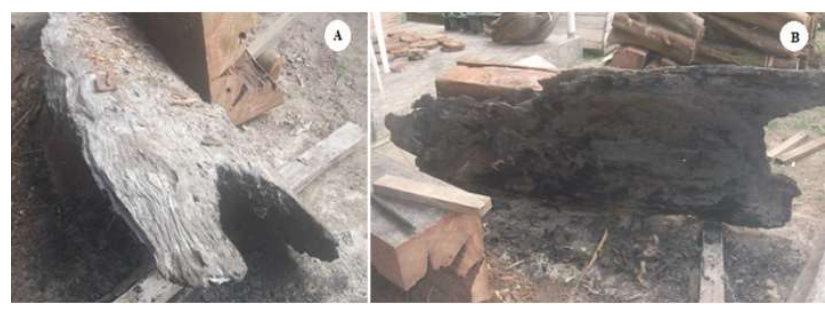

Figura 4. Peça de sucupira-preta com sinais de carbonização nas extremidades (A) e deterioração na parte inferior da peça (B).

Figure 4. Black-sucupira piece with signs of carbonization at the ends (A) and deterioration at the bottom of the piece (B).

$\mathrm{Na}$ Figura 5 é apresentado o trabalho de limpeza da peça de sucupira-preta, efetuada na sua maior parte com machado e machadinha para que pudesse ser retirada toda terra incrustada bem como a madeira degradada concentrada na parte inferior, região de contato desta com o solo. A limpeza final foi executada com jato de água utilizando bomba de pressão. 


\section{Burakouski et al.}

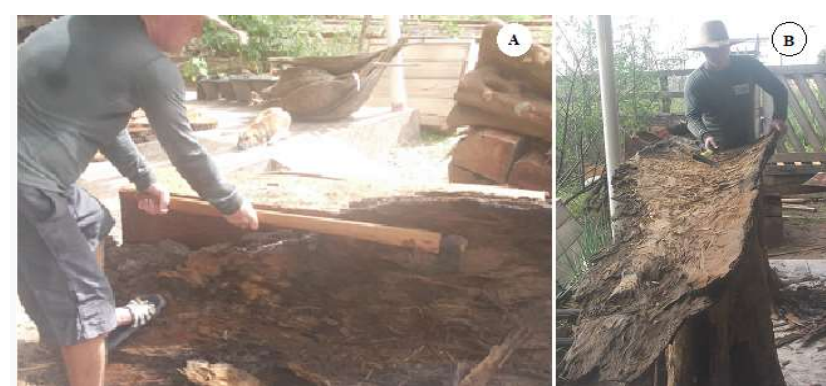

Figura 5. Limpeza com machado (A) e limpeza com machadinha (B).

Figure 5. Ax cleaning (A) and ax cleaning (B).

Na Figura 6 pode-se ver as peças de madeira da espécie quinarana (Geissospermum sericeum Benth) previamente escolhidas e separadas para confecção das bases de sustentação do balcão. Foram utilizadas duas destas toras de madeira as quais tiveram que ser moldadas para se encaixarem adequadamente ao formato angular da base, condição esta que gerou excedente de trabalho tendo em vista a necessidade de sucessivos testes e ajustes até dar encaixe perfeito.

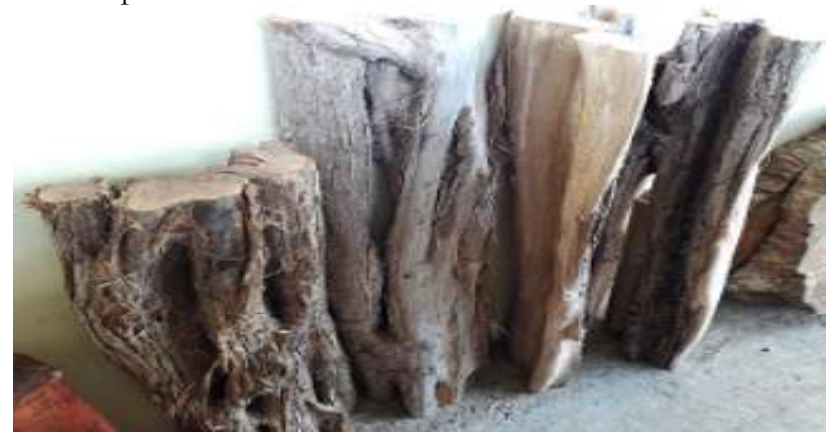

Figura 6. Toras de madeira de quinarana, pré-selecionadas para compor a base do balcão.

Figure 6. Quinarana wood logs, pre-selected to compose the base of the counter.

Para a fixação da parte inferior do balcão utilizou-se travessa de madeira da espécie maçaranduba (Manilkara buberi Ducke) formando uma pequena prateleira, útil para guardar recipientes utilizados no barzinho, sendo o travamento da base feito com a própria madeira. Já a parte superior foi fixada com grandes parafusos franceses (rosca sem fim) de modo a dar resistência e rigidez ao móvel. O Tratamento final foi dado com verniz translúcido para destacar a coloração natural de cada madeira que compõe o móvel, permitindo o contraste entre elas, já que a sucupira-preta tem coloração escura, oposta à coloração amarelada da quinarana.

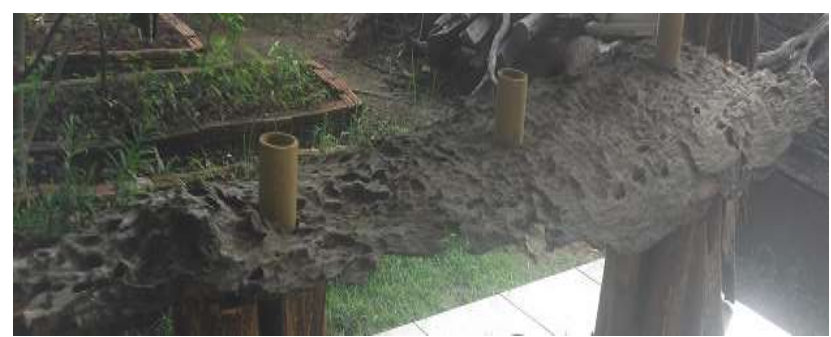

Figura 7. Estruturas de bambu destinadas a fixar a base plana de vidro.

Figure 7. Bamboo structures designed to fix the flat glass base.

Como a superfície da base do balcão mostrou-se muito irregular tanto devido ao formato acanoado da peça como também pelas corrosões naturais presentes e tendo interesse em preservar essas características rústicas e não comprometer sua beleza natural, optou-se por formar uma base plana e nivelada de vidro transparente, a qual foi fixada sobre o balcão de madeira utilizando como separadores três estruturas cilíndricas retiradas de colmos de bambu (Figura 7).

\subsection{Fabricação do aparador de madeira}

$\mathrm{Na}$ Região Norte do Brasil é muito comum ocorrer o desdobro de madeira nativa dentro da floresta utilizando-se apenas a motosserra para retirada das peças de interesse (pranchas, tábuas, vigas, etc.) e desse processo geralmente resultam grandes quantidades de resíduos, haja vista ser utilizada somente a parte íntegra da madeira.

Em várias espécies da floresta amazônica é muito comum o serrador deparar-se com a presença de ocos, então as peças (pranchas, tábuas, vigas, etc.) são cortadas até o ponto em que é possível retirar a parte íntegra da tora, ou seja, até atingir a parte oca, abandonando-se o restante da madeira devido à impossibilidade de retirada de outras peças.

Desta forma uma interessante estrutura retangular envolvida pelo oco se forma tornando-se uma matéria-prima interessante para confecção de mobiliário rústico, podendo a ela dar inúmeras possibilidades de uso quer seja para mesas, bancos, aparadores, etc.

$\mathrm{Na}$ Figura 8 pode-se ver uma estrutura retangular proveniente do desdobro de uma tora de angelim-vermelho (Dinizia excelsa Ducke) encontrada abandonada na floresta e que serviu de base para a confecção do aparador.

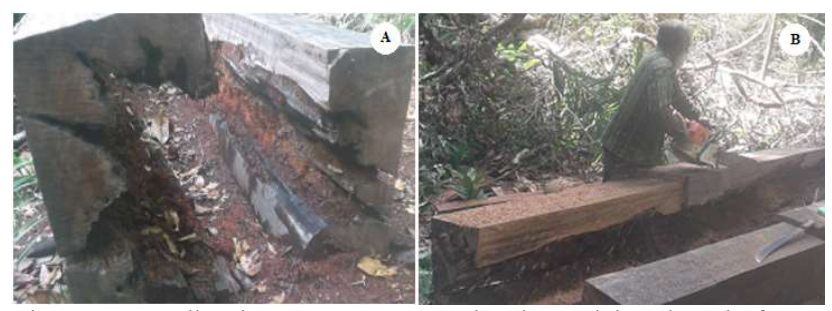

Figura 8. Detalhe da estrutura retangular de madeira vista de frente (A) e serrador separando a peça de madeira para o mobiliário (B).

Figure 8. Detail of the rectangular wooden structure seen from the front (A) and sawmill separating the wooden piece for the furniture (B).

Esta peça foi inicialmente cortada com 1,5m de comprimento, depois limpa com lavadora de pressão e posteriormente lixada nas partes planas com disco flap, acoplado à esmerilhadeira, e manualmente nas áreas irregulares.

Como processo sequencial de fabricação do aparador, foi escavada uma gaveta na parte frontal superior, visando aproveitar a parte maciça da madeira para torná-la mais funcional e possibilitar o uso para guarda de pequenos objetos bem como para reduzir o excesso de seu peso. Para dar sofisticação ao aparador, o mesmo foi entalhado com imagem temática utilizando-se da mesma metodologia descrita para o banco "peça de tora única" (Figura 9).

$\mathrm{Na}$ fase final de fabricação desta peça, uma base de vidro foi colocada na parte interna do aparador para servir de prateleira. O acabamento foi dado com verniz translúcido para acrescentar brilho ao móvel e em sua parte inferior foram fixadas pequenas e resistentes rodinhas comumente utilizadas para facilitar a mobilidade de mobiliários pesados. 


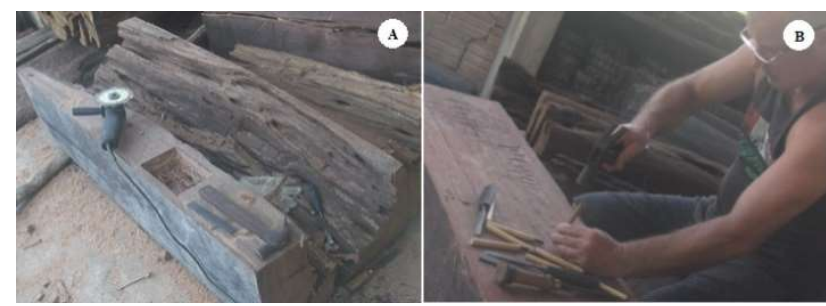

Figura 9. Abertura da gaveta na parte frontal superior do aparador (A) e entalhe com imagem temática feita na madeira (B).

Figure 9. Opening of the drawer on the upper front of the sideboard (A) and carving with thematic image made in wood (B).

\subsection{Fabricação da pia de madeira}

Para a fabricação da pia foram utilizadas madeiras de duas espécies da floresta amazônica, sendo a parte superior da peça, composta pelo lavatório e saboneteira, ambas feitas com madeira da espécie maçaranduba (Manilkara buberi Ducke) e a base de sustentação com madeira da espécie quinarana (Geissospermum sericeum Benth).

O lavatório e a saboneteira da pia originaram-se de uma galhada de maçaranduba, sendo estas inicialmente recortadas com a motosserra em partes menores proporcionais ao tamanho da peça idealizada e posteriormente escavadas com disco de corrente de motosserra acoplado à esmerilhadeira até dar o formato da concavidade desejada (Figura 10).

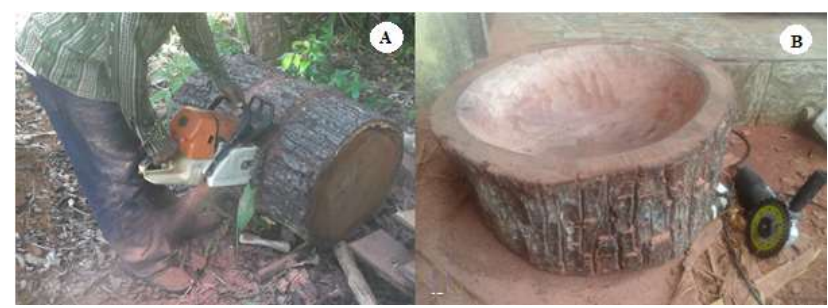

Figura 10. Corte da galhada de maçaranduba para o lavatório da pia de madeira (A) e lavatório da pia de madeira escavada com disco de corrente de motosserra (B).

Figure 10. Cutting of the maçaranduba antlers for the wooden washbasin (A) and excavated wooden washbasin with chainsaw chain disc (B).

Para tirar irregularidades e deixar lisa a superfície escavada foram utilizadas lixas de diversas gramaturas, desde a mais grossa até a mais fina, o que concedeu aspecto totalmente liso à parte escavada da madeira.

Na Figura 11 é exibida uma bifurcação de quinarana utilizada para a base de sustentação da pia, a qual serviu de suporte duplo entre o lavatório e a saboneteira, sendo previamente preparada com a retirada da casca e posterior lixamento da madeira.

A base bifurcada da madeira de quinarana, por apresentar o interior oco foi colocada de modo que esta permaneça à mostra (parte frontal), valorizando a presença do oco e dando um efeito diferenciado ao acabamento da peça.

O acabamento final foi idealizado com recobrimento da cuba da pia utilizando resina poliéster de baixa viscosidade aplicada com pincel a qual depois de seca adquire a consistência acrílica, impermeabilizando a área onde deverá receber água. O mesmo procedimento foi feito com a saboneteira, porém em camada mais fina.

Para a base de sustentação foi dado acabamento com verniz translúcido o que destacou a coloração natural da madeira de quinarana, finalizando assim a peça que ficou com diâmetro do lavatório de $60 \mathrm{~cm}$, largura total de $70 \mathrm{~cm}$ e altura de $80 \mathrm{~cm}$, estando esta última dentro do padrão das pias convencionais.

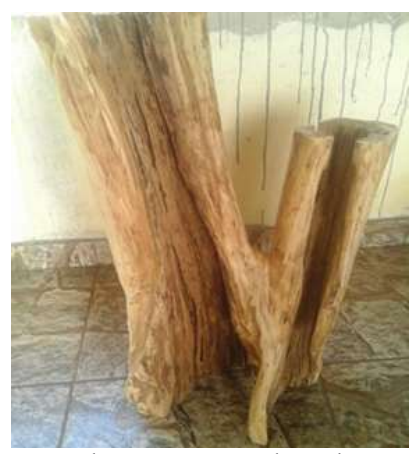

Figura 11. Bifurcação de um tronco de quinarana utilizada como base para suporte do lavatório e da saboneteira.

Figure 11. Bifurcation of a quinarana trunk used as a base to support the washbasin and the soap dish.

\subsection{Fabricação da mesinha de centro com tampo de madeira}

Nesta peça foi utilizada madeira maciça da espécie angelim-pedra (Hymenolobium petraeum Ducke) para o tampo, cortada em formato de disco com espessura reduzida (cerca de $5 \mathrm{~cm}$ ) e diâmetro médio de $74 \mathrm{~cm}$, sendo a base da mesinha confeccionada a partir de um fragmento de tora oca de castanheira-do-brasil (Bertholletia excelsa Bonpl), esta encontrada à beira de uma antiga estrada de acesso, muito provavelmente abandonada no local desde os tempos de abertura da mesma.

$\mathrm{Na}$ Figura 12 pode-se observar os fragmentos ocos de tora de castanheira-do-brasil, os quais após divididos longitudinalmente formaram duas peças semelhantes, sendo as mesmas invertidas, escavadas e moldadas, para dar uma silhueta mais delineada e mais leve à peça e então poder fixálas entre si por meio de parafusos dimensionados adequadamente para formar a base da mesinha.
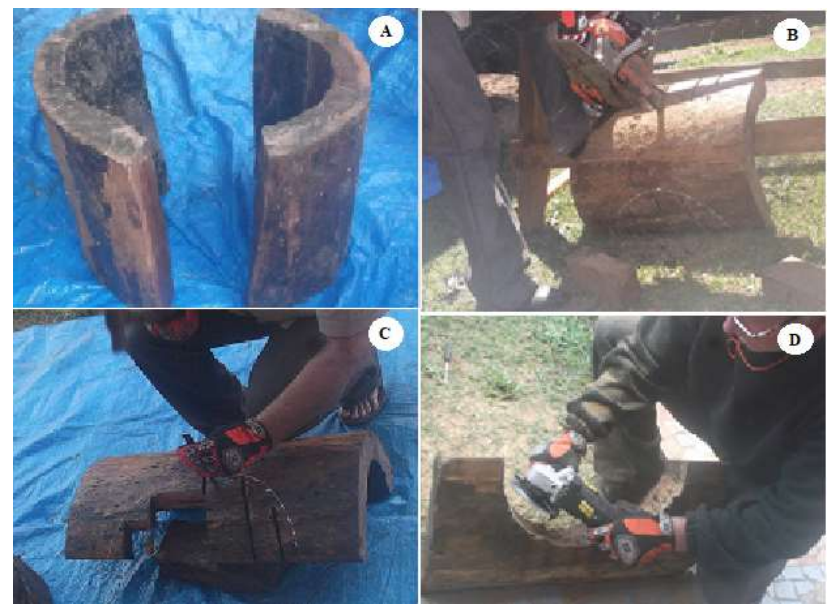

Figura 12. Fragmentos de tora oca (A), escavação da base com motosserra (B), retirada do excesso com formão (C) e aplainamento e moldagem da base com disco de corrente de motosserra acoplado à esmerilhadeira (D).

Figure 12. Hollow log fragments (A), excavation of the base with a chainsaw (B), removal of the excess with a chisel (C) and flattening and molding of the base with a chainsaw chain disc attached to the grinder (D).

Na preparação do tampo utilizou-se plaina elétrica para desempenar a peça e lixamento para dar o acabamento. Este 
ainda foi recoberto com resina cristal formando uma camada de aproximadamente $4 \mathrm{~mm}$ de espessura sobre a madeira e aplicado verniz ao restante da peça. A sequência de aplainamento e recobrimento com resina no tampo pode ser visualizada na Figura 13.

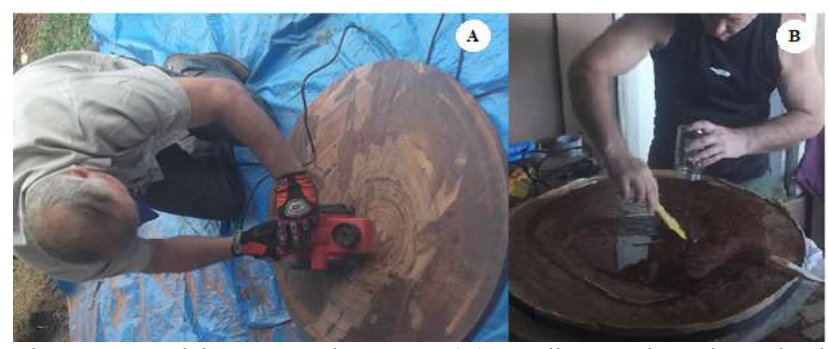

Figura 13. Aplainamento do tampo (A) e aplicação de resina cristal (B).

Figure 13. Top planing (A) and application of crystal resin (B).

\subsection{Fabricação da mesinha de centro com tampo de} vidro

A espécie acariquara (Minquartia guianensis Aubl) é conhecida pela característica do tronco, fenestrado e acanalado, o que por si só já é uma obra de arte da natureza, e uma vez preparada adequadamente pode render variadas opções de uso na movelaria rústica (Figura 14).

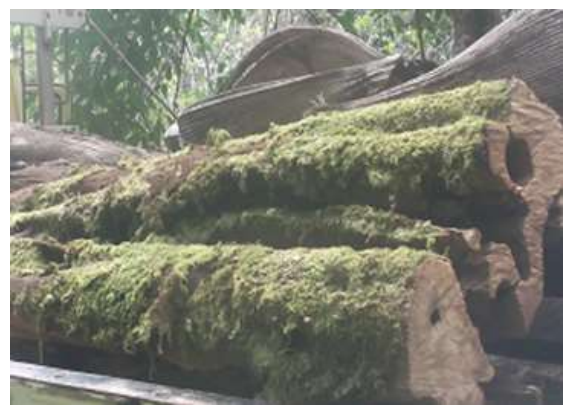

Figura 14. Fuste de acariquara utilizado como base para a mesinha. Figure 14. Acariquara shaft used as a base for the table.

A mesinha de centro com tampo de vidro foi produzida a partir de um fuste de madeira de aquariquara caída na floresta, sendo esta então cortada com $60 \mathrm{~cm}$ de altura da qual foi retirada a casca e o limo nela presente, depois limpa e lixada para posterior envernizamento com a tonalidade cedro conferindo-lhe coloração avermelhada.

Para dar maior requinte à peça e possibilitar visibilidade ao tronco optou-se por colocar um tampo de vidro transparente recortado segundo os contornos irregulares do tronco mantendo uma borda de aproximadamente $15 \mathrm{~cm} \mathrm{e}$ afixado à peça por meio de prolongadores de alumínio $(19 \mathrm{x}$ $20 \mathrm{~mm})$.

\section{RESULTADOS}

Ao todo foram fabricadas seis peças de móveis rústicos, de diferentes tamanhos e graus de complexidade com registro dos detalhamentos individuais em imagens que permitem melhor avaliação dos resultados obtidos.

\subsection{Banco "peça de tora única"}

- Características do móvel: Encosto/Assento - Cedro vermelho (Cedrela fissilis); Base - Castanheira-do-Brasil (Bertholletia excelsa); Travessa - Sucupira (Bowdichia nitida).

- Dimensões: 0,7 m altura; 0,5 m largura; 1,5 m comprimento.
O entalhamento foi a atividade que demandou a maior parcela de tempo na confecção desta peça de mobiliário.

Foi entalhado tanto o encosto quanto o assento do banco de modo a formar uma ilustração panorâmica e complementar entre si, com moinho de roda d'água no encosto, se abrindo no formato de um rio e um pescador ao canto esquerdo no assento (Figura 15).

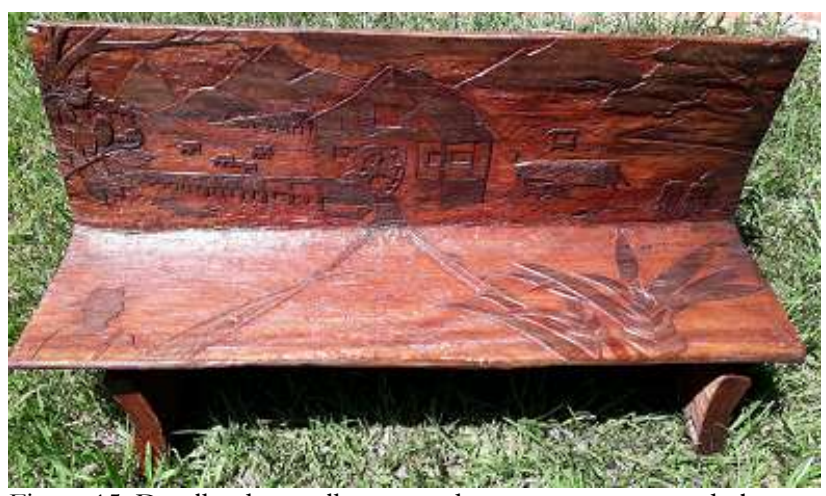

Figura 15. Detalhe do entalhamento do encosto e assento do banco. Figure 15. Detail of the carving of the seat back and seat.

Na Figura 16 é apresentado detalhamento da imagem entalhada no encosto do banco com uma típica paisagem interiorana, cuja temática principal é o moinho de roda d'água com os dutos de água, árvores, montanhas, animais, pilha de lenha e carroça.

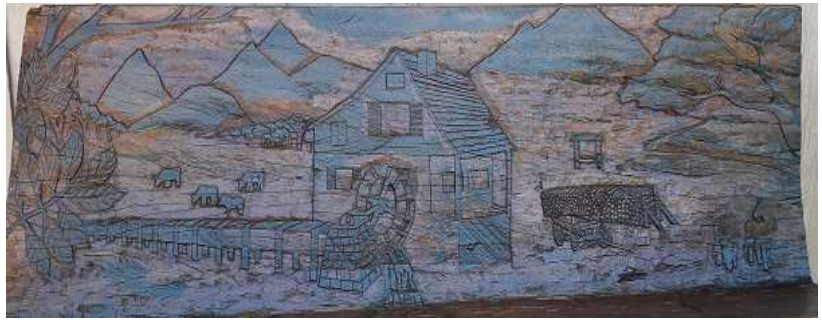

Figura 16. Detalhe da imagem temática no encosto do banco. Figure 16. Detail of the thematic image on the seat back.

$\mathrm{Na}$ Figura 17 é possível observar o detalhamento da parte inferior do móvel, com encaixe da base no fromato curvo do assento e travamento longitudinal com a barra de madeira de sucupira.

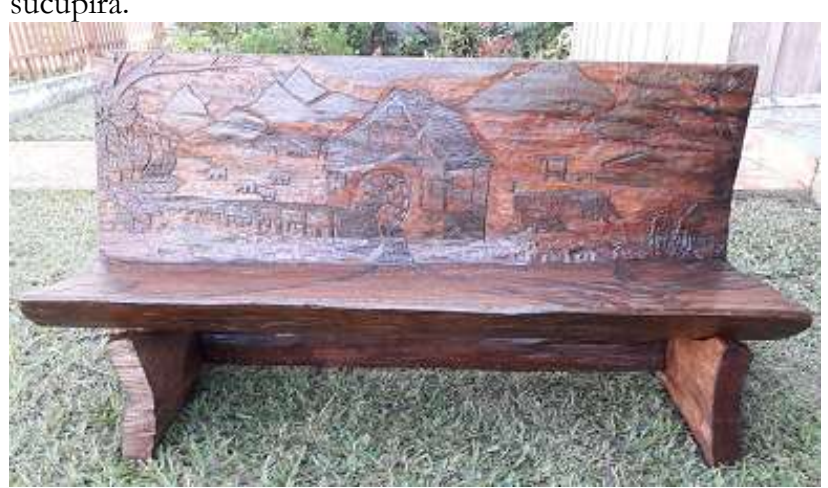

Figura 17. Detalhe do encaixe para fixação da base do banco. Figure 17. Detail of the fitting for fixing the seat base.

\subsection{Balcão para barzinho}

Características do móvel: Balcão - Sucupira-preta (Diplotropis purpurea); Bases - Quinarana (Geissospermum sericeum); Travessa - Maçaranduba (Manilkara buberi).

- Dimensões: 1,2 $\mathrm{m}$ altura; 0,7 $\mathrm{m}$ largura; 2,4 m comprimento. 
O balcão para barzinho é o mobiliário que se destaca pelas dimensões, sendo a maior entre todas as peças fabricadas e o resultado final pode ser visualizado na Figura 18.

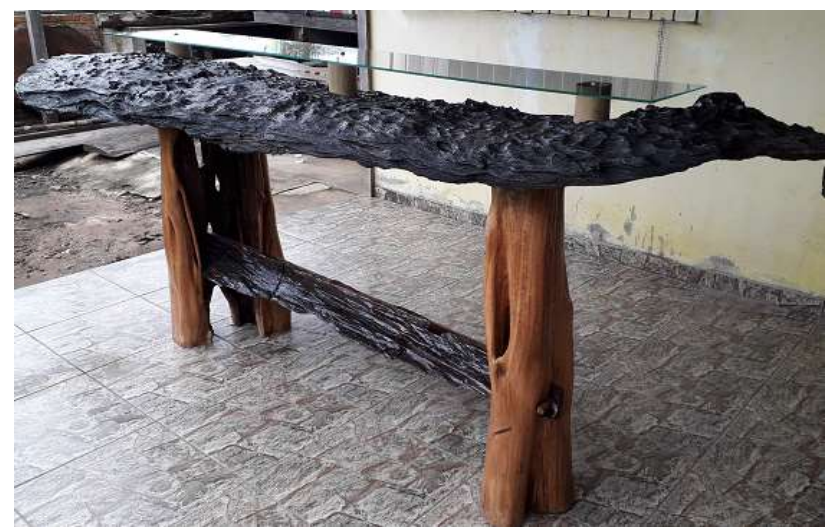

Figura 18. Balcão para barzinho com vidro temperado formando uma base plana na superfície superior.

Figure 18. Bar counter with tempered glass forming a flat base on the upper surface.

\subsection{Aparador de madeira}

- Características do móvel: Peça inteiriça composta por Angelim vermelho (Dinizia excelsa).

- Dimensões: 0,6 m altura; 0,34 m largura; 1,5 m comprimento.

O aparador foi entalhado na parte frontal e também na parte superior da peça com uma imagem temática de um "carro de boi" em uma paisagem sertaneja.

Os adornos que aparecem na imagem foram colocados para mostrar a funcionalidade da peça com a gaveta frontal e prateleira de vidro transparente na parte inferior (Figura 19).

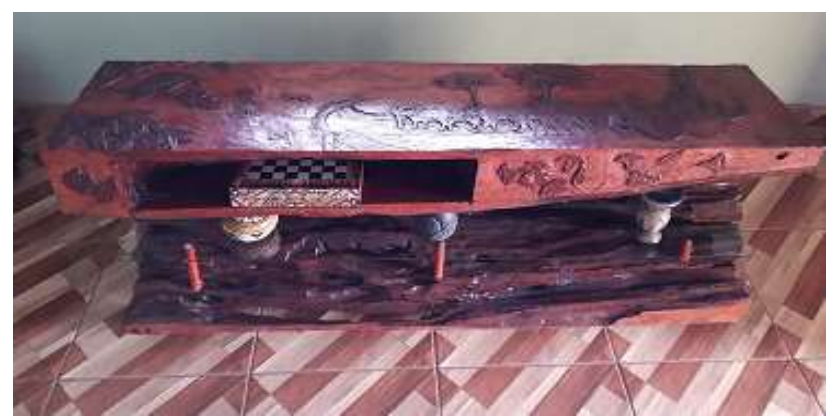

Figura 19. Aparador de madeira de angelim-vermelho com entalhe frontal e superior.

Figure 19. Red angelim wooden sideboard with front and top notch.

Para tornar mais nítida a visualização da imagem entalhada na parte superior do aparador, esta é mostrada separadamente. Pode-se notar que a imagem apresenta tonalidade diversa, pois trata-se da junção de duas fotos (mosaico) para poder dar a visão ampla do entalhe (Figura 20).

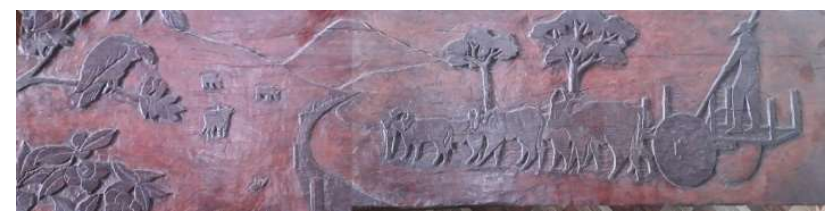

Figura 20: Detalhamento do entalhe na parte superior do aparador. Figure 20. Detailing of the notch on the top of the trimmer.

\subsection{Pia de madeira}

- Características do móvel: Lavatório e saboneteira Maçaranduba (Manilkara buberi); Base - Quinarana (Geissospermum sericeum).

- Dimensões: 0,8 m altura; 0,6 m diâmetro; 0,7 m largura total.

A pia de madeira possui orifício possibilitando acoplar mangueira para escoamento de água. Seu design foi trabalhado para que a mesma tenha ponto de equilíbrio que permita manter-se em pé, porém foi colocado um chumbador de metal na parte posterior do móvel possibilitando fixá-la na parede para dar mais segurança na instalação. O móvel em sua versão final pode ser visto na Figura 21

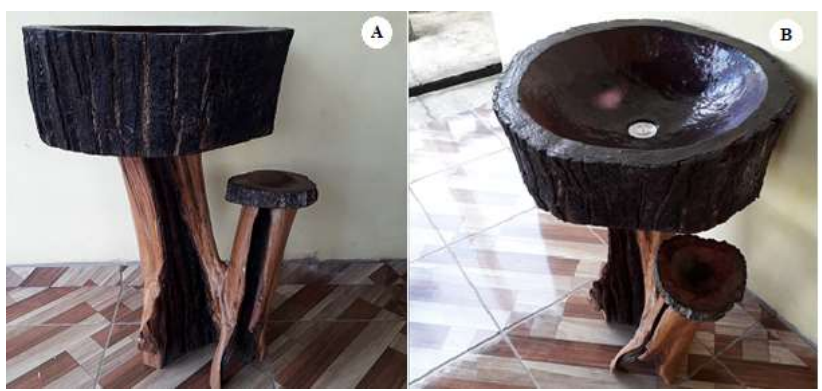

Figura 21. Visão frontal da pia de madeira (A) e visão lateral da pia de madeira (B).

Figure 21. Front view of the wooden sink (A) and side view of the wooden sink (B).

\subsection{Mesa de centro com tampo de madeira}

- Características do móvel: Tampo - Angelim pedra (Hymenolobium petraeum); Base - Castanheira-do-Brasil (Bertholletia excelsa).

- Dimensões: 0,6 m diâmetro; 0,7 m diâmetro.

Como resultado final obteve-se para a mesinha de centro com tampo de madeira, um móvel com base sólida e resistente a qual foi escavada para retirar excessos e assim diminuir o peso e possibilitar um delineamento mais sutil à peça, e tampo brilhante com uma camada transparente de resina cristal para deixar à mostra as características da própria madeira valorizando assim sua aparência natural.

Esta peça é representada em dois ângulos perpendiculares entre si, conforme mostra a Figura 22.

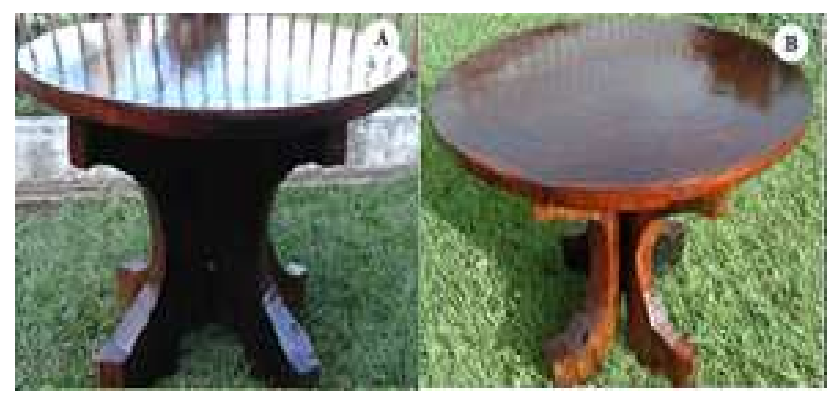

Figura 22. Mesinha de centro vista de frente (A) e mesinha de centro visão lateral (B).

Figure 22. Coffee table seen from the front (A) and coffee table side view (B).

\subsection{Mesa de centro com tampo de vidro}

- Características do móvel: Base - Acariquara (Minquartia guianensis); Tampo de vidro temperado $6 \mathrm{~mm}$.

- Dimensões: 0,6 m altura; 0,55 m diâmetro médio da base;

Nativa, Sinop, v. 9, n. 5, p. 508-517, 2021. 
0,70 m diâmetro médio do tampo.

A acariquara é uma madeira que torna-se extremamente dura depois de seca, o que dificulta sua trabalhabilidade com máquinas e ferramentas, mesmo elétricas, porém seu estilo singular de tronco, todo fendado é uma obra de arte da natureza necessitando de poucas intervenções para se tornar o principal atrativo do mobiliário, conforme podemos ver na Figura 23.

O vidro transparente colocado na peça possibilita deixar à mostra as irregularidades naturais do tronco, permitindo aliar ao mesmo tempo a rusticidade e a sofisticação a este mobiliário.

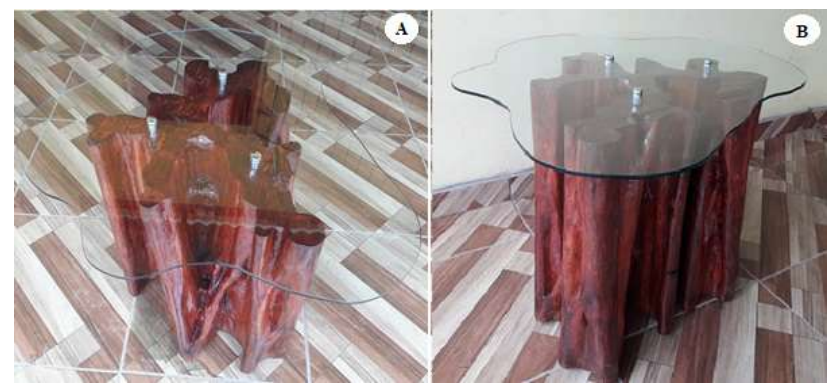

Figura 23. Mesinha de centro vista de cima com a transparência do vidro (A) e mesinha de centro vista de frente destacando o reflexo para delinear seu contorno (B).

Figure 23. Coffee table seen from above with glass transparency (A) and coffee table seen from the front highlighting the reflection to delineate its outline (B).

\section{DISCUSSÃO}

A madeira é a principal matéria-prima que fundamenta esta pesquisa, já que o todo resultado obtido provém do trabalho desenvolvido a partir dela. Martins (2010) enfoca o uso da madeira pela ampla disponibilidade e características de fácil manuseio, a qual sempre foi utilizada pelo homem, sendo um dos primeiros materiais a ser explorado e apesar do aparecimento de materiais sintéticos, a madeira continua a manter uma imensidade de usos diretos e serve de matériaprima para uma grande quantidade de produtos.

Uliana (2010) cita que na região amazônica, a produção madeireira é caracterizada pela máxima retirada de madeira por área, com a exploração de poucas espécies de interesse comercial e pela geração de grande quantidade de resíduos, tanto na floresta quanto na indústria, assim priorizou-se o uso de madeira residual da floresta amazônica para este estudo, considerando-se a grande quantidade deste material descartado na floresta após exploração florestal.

O conhecimento da quantidade e da qualidade dos resíduos madeireiros pode gerar alternativas de uso desse recurso contribuindo com a racionalização dos recursos florestais, bem como gerando novas alternativas econômicas para famílias, aumentando a renda, além de trazer a reflexão do uso sustentável da matéria-prima madeireira (AMARAL et al., 2018).

Os móveis em especial têm relação estreita com a madeira, sendo ainda hoje o material mais difundido na sua fabricação e tamanha é sua influência no cotidiano das pessoas que passou a simbolizar períodos da história do homem cada qual com suas características diferenciadas. Para Mancuso (2012) existe uma linha tênue entre a história em si, a história da arte e a história do mobiliário.

Segundo Carvalho; Bendassolli (2019) o trabalho artesanal pode se apresentar de maneira simples, sendo produzido com poucos elementos e com insumos facilmente encontrados e pouco onerosos, ou ser pomposo, requintado, uma iguaria luxuosa, única em seu preço e/ou valor.

A primeira condição está muito presente nas peças produzidas, pois tiveram como origem material residual parcialmente deteriorado como a peça de sucupira-preta utilizada no "balcão para barzinho", a base de sustentação da "mesinha de centro tampo de madeira" e também a base do "banco peça de tora única", embora a segunda condição também seja vislumbrada, pois foram utilizados materiais acessórios como vidros no "balcão para barzinho", "mesa de centro com tampo de vidro" e no "aparador de madeira" que possibilitaram requinte aos móveis agregando valor de mercado.

Os móveis rústicos têm como característica principal o uso da madeira bruta, a qual preserva as peculiaridades de cada espécie, valorizando a anatomia de seus lenhos e integrando a beleza estrutural dos elementos que compõe à peça a ser produzida. Dessa forma os aparentes defeitos (tortuosidades, ocos, lenhos de reação, nós, troncos acanalados, etc.) tornam-se potenciais atrativos ao design da peça.

Segundo Cecchetti (2019) “os móveis atuais recebem recobrimento de papéis decorativos que simulam características visuais macroscópicas de madeiras naturais, e em alguns casos até simulando a presença de veios e nós" condição esta que já é comum nos móveis rústicos provenientes de madeira residual, ou seja, o cliente já está comprando um produto genuíno, isto é um fator de extrema importância na valorização do mobiliário rústico.

A madeira serrada é a matéria-prima mais nobre da indústria moveleira, pois tem como característica diferentes fibras e colorações. Além disso, apresenta alta resistência física e mecânica, durabilidade e usinabilidade. Pode ser emoldurada, torneada ou entalhada (HUSQWARNA, 2016).

A forma artesanal de fabricar os móveis considera que estes não precisam necessariamente de máquinas e equipamentos industriais sofisticados, podendo ser produzidos com máquinas e ferramentas de uso doméstico e até mesmo ferramentas manuais sem a necessidade de um elevado grau de investimento em infraestrutura.

Amaral (2018) constatou que em algumas indústrias moveleiras da região amazônica, havia pouca inovação tecnológica sendo operacionalizadas com equipamentos ultrapassados frequentemente produzidos ou adaptados pelos próprios operadores, que geralmente aprendem a profissão de marceneiro com os pais e familiares.

Embora a fabricação dos móveis não tenha exigido aparatos sofisticados, foi verificada a necessidade do uso de uma serra fita ou serra circular para desdobro da madeira, em especial de maiores dimensões, para melhorar a qualidade dos cortes retos, pois quando efetuados com motosserra não apresentaram bom alinhamento e angulação. Alves (2019) cita que o corte de madeira é um processo com características altamente variáveis devido a sua estrutura, caracterizada pela elevada anisotropia, ou seja, é fortemente depende das direções de corte (longitudinal, radial e tangencial).

Outro ponto relacionado ao processo de produção e que caracterizaram duas das peças fabricadas foram os entalhes ornamentais, apresentados no "banco tora única" e no "aparador de madeira" como forma de enriquecer os detalhes e assim agregar maior valor aos móveis. Segundo Alzier (2017), a dureza e a densidade da madeira definem de que 
forma a peça pode ser entalhada, pois essas características determinam a técnica de acabamento. Quanto maior a dureza e a densidade da madeira trabalhada, maior a possibilidade dela tolerar um entalhe mais fino, ao passo que as madeiras macias permitem entalhes de menor precisão.

Atualmente uma das maiores dificuldades em se trabalhar com móveis rústicos está relacionada a obtenção da madeira bruta, peças de maiores dimensões e espécies nobres, condições que muitas vezes inviabilizam os projetos pela indisponibilidade ou até mesmo inexistência de material de boa qualidade na região. Com a realização de estudos mais aprofundados referentes as caracterizações tecnológicas, os resíduos podem ter aproveitamento na fabricação de móveis e pequenos artefatos de madeira, agregando mais valor, além de colaborar para o manejo sustentável (RIBEIRO et al., 2016).

O segmento de móveis está entre os mais importantes da Indústria de Transformação no país, não só pela importância do valor da sua produção, como também pelo seu potencial de geração de empregos (TEIXEIRA; FIGUEIREDO, 2017).

Segundo Câncio et al. (2021), o setor madeireiro na Amazônia contribui expressivamente para a economia local, regional e nacional, assim como para a geração de empregos e desenvolvimento. No entanto, enfrenta entraves como a falta de políticas e ações voltadas para a consolidação de uma base florestal que venha atender as demandas de quem depende da madeira como matéria prima em pequenos municípios da Amazônia.

A criação e produção de móveis com materiais renováveis bem como a avalição do seu ciclo de vida, é justificada pela crise dos recursos renováveis que o planeta sofre. O design envolve uma série de elementos e etapas de elaboração que vão além da aparência, que podem atrair a atenção do consumidor causando uma impressão favorável não só do produto como da imagem da empresa. O consumidor está exigente e procura exclusividade, sendo importante que o produto apresente um conforto visual (GEIB; OLIVO, 2015).

$\mathrm{Na}$ região onde os móveis deste trabalho foram produzidos há uma grande dificuldade em se mudar a concepção dos moveleiros locais para abertura do mercado a novidades, por isso a forma de produzir o mobiliário ainda é fortemente atrelado ao tradicionalismo local. Oliveira (2009) num estudo nesta mesma região, concluiu que "Na verdade realmente é cultural, porque os móveis são feitos de acordo com as necessidades regionais e não a partir das demandas de mercado tanto falado pelos consultores e pouco entendido pelos moveleiros".

Outras dificuldades presentes na região são: acesso precário, distância dos grandes centros consumidores e principalmente a ausência total de divulgação de seus trabalhos o que restringe o comércio apenas à venda local. Motta; Garcia (2006) há muito tempo já correlacionaram essa última condição quando citaram como importante fonte competitiva para as empresas o desenvolvimento de canais de comercialização.

Uma alternativa atual para sanar este déficit seria o uso de canais de divulgação via internet, cuja abrangência ultrapassa as barreiras culturais e de distâncias. Vieira et al. (2019), numa pesquisa com artesãos e escultores de madeira na região do nordeste brasileiro verificaram dificuldade deles se manterem financeiramente, pois esse trabalho não gerou renda fixa. No entanto, o uso de tecnologias de informação favoreceu a comercialização dos produtos, especialmente verificada na utilização de mídias sociais.

Este estudo demonstra que o trabalho artesanal com resíduos de madeira da floresta amazônica pode contribuir para desenvolvimento de atividade local que esteja voltada ao cumprimento de alguns dos principais objetivos de desenvolvimento sustentável da ONU, entre eles: promover o crescimento econômico, inclusivo e sustentável; fomentar a inovação; reduzir a desigualdade dentro dos países; assegurar padrões de produção e de consumo sustentáveis; proteger, recuperar e promover o uso sustentável dos ecossistemas terrestres e gerir de forma sustentável as florestas (NAÇÕES UNIDAS, 2021).

\section{CONCLUSÕES}

Os resíduos de madeira oriundos de limpeza e exploração de áreas de floresta nativa na região norte do País se mostraram excelente fonte de matéria-prima para movelaria rústica, possibilitando múltiplas alternativas de designs em função das possibilidades de personalização do mobiliário.

Grãs irregulares de madeira de espécies florestais nativas dificultam o trabalho de entalhamento das peças, as quais tem que ser esculpidas obedecendo ao sentido das fibras caso contrário corre-se o risco de lascar a madeira e comprometer o desenho que fora idealizado para o móvel, embora a prática do artesão na arte do entalhe seja o principal diferencial nesta atividade.

O uso de outros materiais como vidros e resina acrílica para revestimento e preenchimento da madeira residual possibilita outras opções de design para o mobiliário, aliando a rusticidade à sofisticação em uma mesma peça, aumentando a sua valoração no mercado.

A produção artesanal de móveis rústicos é possível sem o uso de máquinas e ferramentas sofisticadas e a transformação de resíduos descartados na floresta em móveis rústicos que podem ser comercializados é uma forma de abrir novos caminhos ao empreendedorismo local.

Pensando em uma produção comercial dos móveis rústicos, parcerias com empresas que exploram madeira sob o regime de PMFS (Plano de Manejo Florestal Sustentável) na região ajudariam na obtenção dos resíduos utilizados, inclusive em relação a comprovação de origem da madeira.

Estudos que tenham relação com design de mobiliário, possibilidades de uso de outros materiais e acessórios para delinear novos formatos aos móveis, possibilitando unir o rústico com o requinte do moderno e, ainda, o conhecimento de tendências e preferências dos consumidores podem tornar mais qualificado e profissional o trabalho do artesão, facilitando a inserção destes produtos no mercado, ganhando margem de competitividade frente aos produtos de outras regiões.

O conhecimento da potencialidade do mercado de móveis rústicos pelos moveleiros locais pode mudar a concepção de seu trabalho tradicional para a oferta deste tipo de produto artesanal ao mercado, buscando maior agregação de valor e renda local. Para isso, podem ser utilizadas as máquinas e ferramentas habituais, sem a necessidade de investimentos, adaptando-as facilmente a nova produção.

Outro ponto importante refere-se à assessoria de instituições voltadas à capacitação e promoção da nova atividade, a exemplo do SEBRAE, que pode atuar principalmente na assistência do moveleiro para divulgação e 
logística de seus produtos até os grandes centros consumidores, pontos esses que são considerados os principais gargalos ao desenvolvimento da atividade na região.

\section{REFERÊNCIAS}

ALVES, R. M. G. F. Análise do processo produtivo de serras circulares para o corte de madeira na empresa FREZITE®. Instituto Superior de Engenharia do Porto. 2019. 160p. http:// hdl.handle.net/10400.22/15689

ALZIER, K. S.; SCHWEICKARDT, K. H. S. C.; WEIL, A. G. O artesanato de Novo Airão: uma estratégia social para conservação. Revista Terceira Margem Amazônica. v2, n.9, Jul/Dez, 17p, 2017. https://doi.org/10.36882/2525-4812.2017v2i9p\%25p

AMARAL, D.; ZAÚ, A. S.; GAMA, D. C.;ALBUQUERQUE, E.; SILVA, F. J. Aproveitamento de resíduo madeireiro em um município amazônico. Revista Biodiversidade, v.17, n2, p. 22-33, 2018.

ARAÚJO, H. J. B.. Relações funcionais entre propriedades físicas e mecânicas de madeiras tropicais brasileiras. Revista Floresta, Curitiba, PR, v. 37, n. 3, set./dez. 2007.

BARROS, P. L. C.; NUMAZAWA, S.; BARROS, D. S. Quantificação de resíduos de exploração e de árvores de queda natural em florestas manejadas na Amazônia: O caso Cikel. Brasil Verde Madeiras. Relatório técnico. 2007.

BRAZ, R. L.; NUTTO, L.; BRUNSMEIER, M.; BECKER, G.; SILVA, D. A. Resíduos da colheita florestal e do processamento da madeira na Amazônia - uma análise da cadeia produtiva. Journal of Biotechnology and Biodiversity, v. 5, n. 2, p. 168-181, 2014.

CÂNCIO, I. A. P.; FONSECA, R.; SOUSA, P. S.; GUIMARÃES, D. F. S. Caracterização da cadeia produtiva de madeira para movelaria e carpintaria naval em Óbidos, Pará. Nature and Conservation, v.14, n.2, p.84-99, 2021. http://doi.org/10.6008/CBPC23182881.2021.002.0009

CARVALHO. D. S.; BENDASSOLLI. P. Processo de significação no trabalho para trabalhadores artesanais atuando em uma capital do nordeste brasileiro. Revista Psicologia e Sociedade, v.31, p. e181444, 2019. https://doi.org/10.1590/1807-0310/2019v31181444

CECCHETTI, L.; RAZERA, D. L. A madeira redesenhada: considerações sobre o design de superfície no mobiliário planejado brasileiro. Revista Design \& Tecnologia, v.09, n.19, $\quad$ p.77-86, 2019 https://doi.org/10.23972/det2019iss19pp77-86

GEIB, V. R.; OLIVO, V. E. Móvel de lavabo utilizando madeira de demolição como matéria prima. Revista Científica Tecnológica, v.3, n.2, p.1-9, 2015.

HERNANDES, C. A. A Organização do Trabalho Artesanal e a Questão do Não- Crescimento, Tese - Programa de Mestrado e Doutorado em Administração, Área de Concentração: Organizações, Gestão e Sociedade, Universidade Positivo, 2016.

HUSQVARNA. E-book. As principais madeiras brasileiras e possibilidades de uso. Ano 1. Husqvarna: n. 8, Janeiro, 2016.

INSTITUTO DE COMUNICAÇÃO E INFORMAÇÃO CIENTÍFICA E TECNOLÓGICA EM SAÚDE (ICICT); FUNDAÇÃO OSWALDO CRUZ (FIOCRUZ). Queimadas na Amazônia e seus impactos na saúde: $\mathrm{A}$ incidência de doenças respiratórias no sul da
Amazônia aumentou significativamente nos últimos meses. $3^{\circ}$ Informe técnico do Observatório de Clima e Saúde. Setembro de 2019. 15p.

MANCUSO, C. Arquitetura de interiores e decoração; A arte de viver bem. Porto Alegre: Sulina, 2012. 239p.

MARTINS, T. F. R. M. Instituto Superior Técnico. Universidade Técnica de Lisboa. 2010. 165p.

MOTTA, F. G.; GARCIA, R. C. Inovação da Indústria de Móveis do Brasil - esforços empresariais e inserção das empresas nos mercados. XXVI Simpósio de Inovação Tecnológica. Gramado. RS. 2006.

NAÇÕES UNIDAS. BRASIL. Objetivos de Desenvolvimento Sustentável. 2021. Acesso em: 29/10/2021. Disponível em: https://brasil.un.org/pt$\mathrm{br} / \mathrm{sdgs}$

NUMAZAWA, C. T., NUMAZAWA, S., PACCA, S., JOHN, V. M. Logging residues and $\mathrm{CO} 2$ of Brazilian Amazon timber: two case studies of forest harvesting. Resources, Conservation and Recycling, v. 122, p. 280$285,2017$.

OLIVEIRA, A. M. Fatores culturais: potencialidades ou entraves no setor moveleiro do município de Laranjal do Jari-AP? Revista Eletrônica de Humanidades. UNIFAP, n. 2, dez., 2009.

PEREIRA, A. F. Design para a sustentabilidade: melhoria de produtos e processos e valorização da identidade local Estudos em Design. Revista (online). Rio de Janeiro: v. 20, n. 2, p.1-15, 2012.

RIBEIRO, R. B. S.; GAMA, J.R.V.; SOUZA, A. L.; LEITE, H. G.; SOARES, C. P. B.; SILVA, G. F. Métodos para estimar o volume de fustes e galhos na floresta nacional do tapajós. Revista Árvore. Viçosa-MG, v.40, n.1, p.8188, 2016. https://doi.org/10.1590/010067622016000100009

SILVA, L. F. F. da; CASTRO, A. R. S. de; OLIVEIRA, R. S.; SILVA, S. S. da; PAMPLONA, V. M. S.; BARROS, D. de S.; NOBRE, J. R. C.; NUMAZAWA, S. Seleção de espécie, temperatura e tempo de carbonização na produção de carvão vegetal com resíduos madeireiros da Amazônia. Pesquisa Florestal Brasileira, [S. 1.], v. 40, 2020. DOI: 10.4336/2020.pfb.40e201801737.

TEIXEIRA, M. D. J.; FIGUEIREDO, A. M. R. Análise intersetorial e espacial da cadeia produtiva da madeira e móveis na economia de Mato Grosso: uma contribuição para identificação de APLS. Revista Brasileira de Gestão e Desenvolvimento Regional. v. 13, n. 2, p. 103-128, maiago/2017.

ULIANA, L. R. Aplicação da tomografia de impulso na avaliação da qualidade do lenho de árvores de maçaranduba, Manilkara huberi (Ducke) Chevalier. Tese Doutorado em Recursos Florestais. Escola Superior de Agricultura Luiz de Queiroz, Universidade de São Paulo, Piracicaba, 2010. 157p.

VIEIRA, C. L. S.; SOUSA, P. A.; GRANGEIRO, R. R. Carreira profissional no artesanato: um estudo com artesãos escultores em madeira. Revista de Carreiras e Pessoas. v.9, n.1, p.9-27, 2019. https://doi.org/10.20503/recape.v9i1.37073

VIEIRA, G. S. O. Artesanato, Identidade e Trabalho. Tese Programa de Pós-Graduação em Sociologia da Faculdade de Ciências Humanas, UFG, Goiás. 2014. 